\section{Necrotizing enterocolitis and focal intestinal perforation in neonatal intensive care units in the state of Baden-Württemberg, Germany}

\author{
Thomas Böhler,1 Ingo Bruder,2 \\ Peter Ruef, 3 Jörg Arand,4 \\ Manfred Teufel,5 Matthias Mohrmann,6 \\ Roland Hentschel7 \\ 1Medical Service of Statutory Health \\ Insurance in Baden-Württemberg, \\ Karlsruhe; 2Regional Office for Quality \\ Assurance in Hospitals, Hospital \\ Federation Baden-Württemberg, \\ Stuttgart; ${ }^{3}$ Childrens' Hospital, SLK- \\ Klinikum, Heilbronn; 4Department of \\ Neonatology, Children's Hospital, \\ University of Tübingen, Tübingen; \\ ${ }^{5}$ Childrens' Hospital, Böblingen; 6 Medical \\ Service of Statutory Health Insurance in \\ Baden-Württemberg, Lahr; ${ }^{7}$ Department \\ of Neonatology, Children's Hospital, \\ University of Freiburg, Freiburg, \\ Germany
}

\section{Abstract}

In preterm infants with very low birth weight (VLBW) $<1500 \mathrm{~g}$ the most important acquired intestinal diseases are necrotising enterocolitis (NEC) and focal intestinal perforation (FIP). We analyzed data of the neonatology module of national external comparative quality assurance for inpatients in the state of Baden-Württemberg, Germany. Between 2010 and 2012, 59 of 3549 VLBW infants developed FIP $(1.7 \%), 128$ of them NEC (3.6\%). In approximately $3 \%$ of infants with $\mathrm{BW}<1000 \mathrm{~g}$ FIP was diagnosed, which was nearly 9 times more often than in infants with BW between 1250 and $1499 \mathrm{~g}$ (FIP frequency $0.36 \%$ ). NEC frequency increased with decreasing $\mathrm{BW}$ and was more than 10 times higher in the smallest infants (BW<750 g: 7.87\%) compared to those with BW between 1250 and $1499 \mathrm{~g}(0.72 \%)$. The BW limit of $1250 \mathrm{~g}$ differentiates between groups of patients with distinguished risks for NEC and FIP.

\section{Introduction}

In its recently updated directive of quality assurance in the care of term and preterm newborn infants, 1 the Federal Joint Commission (Gemeinsamer Bundesauss chuss, G-BA), determines that a level 1 perina- tal center (PNC) - offering the highest level of perinatal care in Germany - has to guarantee both the presence of appropriate structures for immediate surgical treatment of preterm infants with a birth weight (BW) $<1250 \mathrm{~g}$, and the availability of qualified surgeons for these patients. Patients with a BW of $1250 \mathrm{~g}$ and above (i.e., those usually treated in level 2 PNC) may be transferred to PNC level 1 with on-site pediatric surgery in case of need.

Necrotising enterocolitis (NEC) and focal (syn. idiopathic or spontaneous) intestinal perforation (FIP) are the most important acquired intestinal diseases in preterm infants with very low birth weight $<1500 \mathrm{~g}$ (VLBW). ${ }^{2}$ In preterm NEC, feeding difficulties, bacterial overgrowth, ileus and compromise of innate intestinal defenses may cause inflammation in intestinal villi and ischemia. ${ }^{3}$ Most infants with FIP are extremely premature, develop gastrointestinal symptoms during their first week of life, and show rapid progress towards serious life-threatening illness. ${ }^{4-6}$ Infants with NEC may be older and more mature at birth, but NEC and FIP may be clinically indistinguishable and definitive diagnosis often requires intervention of a pediatric surgeon. 7,8

In Germany, information on the epidemiology of NEC is collected and analyzed in yearly intervals in the database of the neonatology module of the national external comparative quality assurance measures for inpatient care (Externe stationäre Qualitätssicherung, EsQS), legally based on Social Code Book V ( $\$ 137$ SGB V). ${ }^{9}$ Data on the epidemiology of FIP can be retrieved from the list of documented diagnoses in a given case, but this information has not been systematically analyzed in the past.

PNCs have to publish only data on the frequency of NEC needing surgical intervention, but not on the frequency of FIP. ${ }^{9}$ Yet, both parameters may be used as indicators of different aspects of quality of care. It has, however, been questioned whether PNC level 1 need on-site pediatric surgery to be able to care for VLBW infants, mainly because the actual risk for FIP, NEC and other surgical emergencies could not be exactly quantified in these patients using data from German hospitals. ${ }^{10}$ We therefore reviewed the documentation of hospitals in Baden-Württemberg from 2010 to 2012 in order to clarify the following questions: i) Do differences in the frequency of NEC and FIP between birth weight strata of VLBW infants indicate a greater need for surgical intervention in PNC level 1 compared to level 2? ii) How does the incidence of NEC and FIP differ between the single hospitals? iii) How do hospital-specific frequencies of NEC and FIP relate to the total number of VLBW infants admitted with a $\mathrm{BW}<1250 \mathrm{~g}$ ?
Correspondence: Thomas Böhler, Medizinischer Dienst der Krankenversicherung (MDK) BadenWürttemberg, Begutachtungs- und Beratungszentrum (BBZ) Karlsruhe, Steinhäuserstrasse 7a, 76135 Karlsruhe, Germany.

Tel.: +49.721.912.61450 - Fax: +49.721.912.614554. E-mail: thomas.boehler@mdkbw.de

Key words: neonatology, pediatric surgery, quality assurance, German Federal Joint Commission, extremely low birth weight infants.

Acknowledgements: we gratefully acknowledge the help of Thomas Floren (GeQiK) with data management and statistical analysis.

Contributions: TB initiated and designed the study, was involved in data interpretation, and wrote the first draft of the manuscript. IB performed data analysis and participated in study design and writing of the first draft of the manuscript. All other authors were involved in study design, data interpretation, and writing of the manuscript.

Conflict of interests: the authors declare no potential conflict of interests.

Received for publication: 6 December 2013

Revision received: 11 January 2014.

Accepted for publication: 12 January 2014.

This work is licensed under a Creative Commons Attribution NonCommercial 3.0 License (CC BYNC 3.0).

CC Copyright T. Böhler et al., 2014

Licensee PAGEPress, Italy

Pediatric Reports 2014; 6:5194

doi:10.4081/pr.2014.5194

\section{Materials and Methods}

Data from hospitals in the state of BadenWürttemberg, Germany, which were submitted to the regional office for quality assurance in hospitals (GeQiK $\left.{ }^{\circledR}\right)$ for the years 2010, 2011, and 2012, were analyzed. The numbers of infants with FIP were extracted from the neonatology module of EsQS (neonatal dataset) using the documentation of each patient's diagnoses at the time of hospital discharge or death (ICD-10-GM: P78.0). The numbers of infants with surgically treated FIP were extracted from each patient's list of diagnoses of surgery ( 5 surgical interventions with their main diagnosis can be documented per stage in the hospital).

The numbers of infants with NEC were extracted from the documentation of diagnoses at the time of hospital discharge or death (ICD10-GM: P77) and/or the documentation of NEC stage II and above according to the modified Bell's classification in the neonatal dataset.11 
The numbers of infants with surgically treated NEC were extracted from the neonatal dataset using the item NEC treated surgically. For both FIP and NEC, numbers of patients undergoing inter-hospital transfer were derived from data sets giving the key 06 (= transfer to another hospital), while numbers of deaths were calculated from data sets giving the key 07 (= death), according to pre-defined reasons for hospital discharge. ${ }^{12}$ All patient data were analyzed after stratification according to birth weight in intervals of $250 \mathrm{~g}$. Minimum, maximum and mean values of disease frequencies and the respective coefficients of variation were calculated using MS Excel 2010.

\section{Results}

Table 1 shows data from newborn infants treated in hospitals in Baden-Württemberg in the years 2010 to 2012. In 3549 VLBW infants, 57 cases (1.7\%) of FIP and 128 cases (3.6\%) of NEC were documented. The rate of acquired intestinal disease was higher in infants with a BW<1250 g [ $n=2439$; FIP: $n=55$ (2.3\%); NEC: $\mathrm{n}=120(4.9 \%)]$ than in infants with a BW from 1250 to $1499 \mathrm{~g}$ [ $\mathrm{n}=1110$; FIP: $\mathrm{n}=4(0.36 \%)$; NEC: $n=8(0.72 \%)]$. Approximately half of the infants with FIP and/or NEC were treated surgically. Among those VLBW infants with acquired intestinal disease who were not operated, 6 of 17 infants diagnosed with FIP and 9 of 45 infants diagnosed with NEC died.

Figure 1 illustrates the differences in frequencies of FIP and NEC between different BW strata for both diseases separately. In the years
2010 to 2012, FIP was diagnosed on average in 1 out of 60 VLBW infants, while 1 out of 28 developed NEC. The frequency of FIP was similar in all infants with a BW $<1000 \mathrm{~g}$ (approxi- mately $3 \%$ ) but was nearly 9 times higher than in infants with a BW between 1250 and $1499 \mathrm{~g}$ $(0.36 \%)$. The frequency of NEC increased with decreasing $\mathrm{BW}$ and was more than 10 times

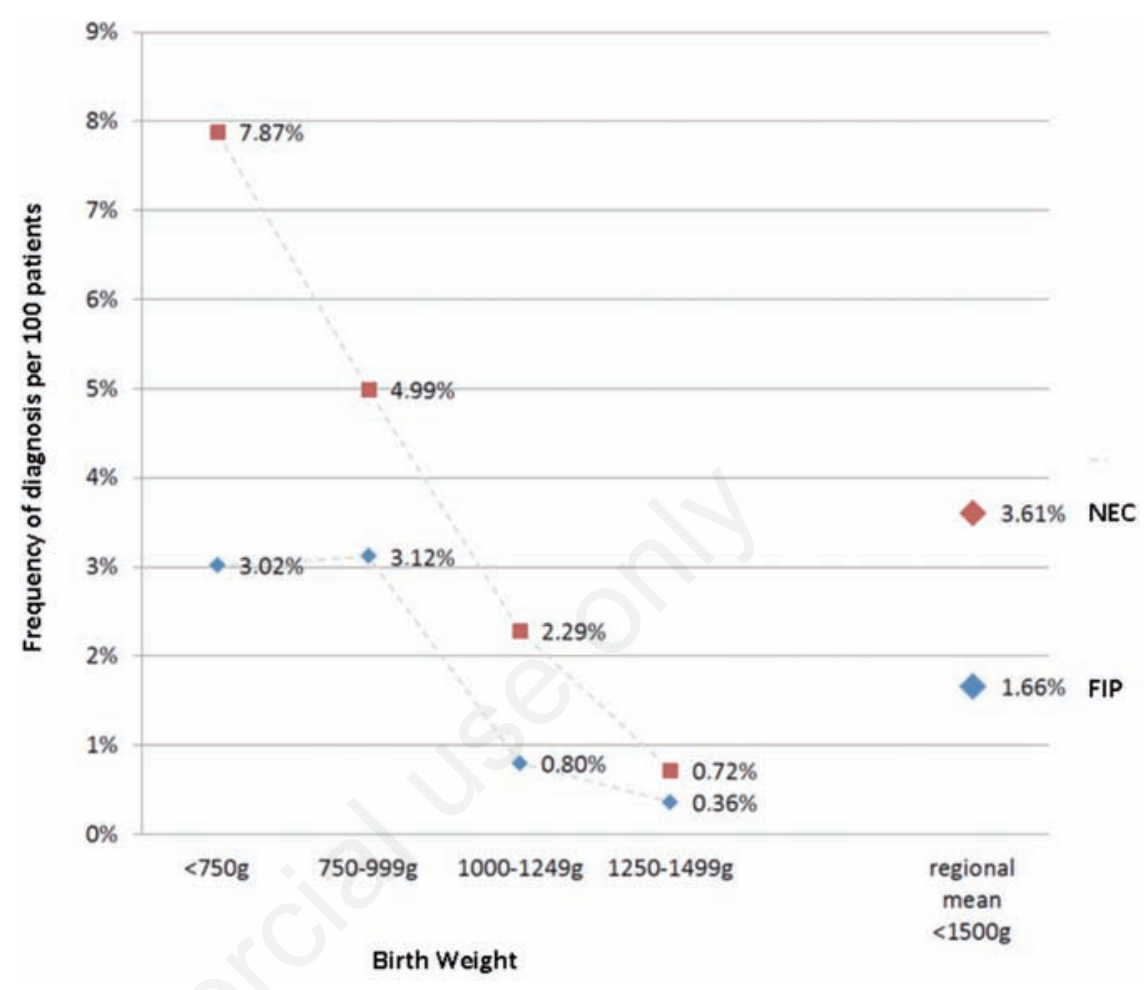

Figure 1. Cumulative regional frequency of acquired intestinal diseases per 100 VLBW infants in Baden-Württemberg in the years 2010 to 2012. Patients were stratified by birth weight in intervals of $250 \mathrm{~g}$ each. In all birth weight strata, rates of necrotizing enterocolitis (NEC) are at least twice as high as the rates of focal intestinal perforation (FIP).

Table 1. Occurrence of neonatal focal intestinal perforation (FIP) and necrotizing enterocolitis (NEC) in hospitals in BadenWürttemberg during the years 2010 to 2012. Please note that the neonatal dataset does not allow combined patient follow-up after inter-hospital transfer; there may be both underreporting and overreporting of FIP and NEC (and related procedures).

\begin{tabular}{|c|c|c|c|c|c|c|c|}
\hline Birth weight & $<750 \mathrm{~g}$ & $\begin{array}{l}750 \text { to } \\
999 \mathrm{~g}\end{array}$ & $\begin{array}{l}1000 \text { to } \\
1249 \mathrm{~g}\end{array}$ & $\begin{array}{l}1250 \text { to } \\
1499 \mathrm{~g}\end{array}$ & $<1500 \mathrm{~g}$ & $\geq 1500 \mathrm{~g}$ & Total \\
\hline Total number of admissions & 762 & 802 & 875 & 1110 & 3549 & 30,595 & 34,144 \\
\hline FIP: diagnosis documented at discharge (ICD-10-GM: P78.0) & 23 & 25 & 7 & 4 & 59 & 16 & 75 \\
\hline FIP with surgical procedure & 12 & 11 & 2 & 1 & 26 & 7 & 33 \\
\hline FIP with surgical procedure thereof referral from other hospital & 4 & 5 & 1 & 1 & 11 & 3 & 14 \\
\hline FIP without surgical procedure & 6 & 7 & 2 & 2 & 17 & 2 & 19 \\
\hline $\begin{array}{l}\text { FIP without surgical procedure thereof transferred to another } \\
\text { hospital }\end{array}$ & 1 & 5 & 2 & 1 & 9 & 2 & 11 \\
\hline FIP without surgical procedure thereof deceased & 3 & 2 & 0 & 1 & 6 & 0 & 6 \\
\hline $\begin{array}{l}\text { NEC stage } \geq 2 \text { documented in data set or diagnosis documented } \\
\text { at discharge (ICD-10-GM: P77) }\end{array}$ & 60 & 40 & 20 & 8 & 128 & 53 & 181 \\
\hline NEC treated with surgery & 30 & 24 & 12 & 4 & 70 & 12 & 82 \\
\hline NEC with surgical procedure not specific for NEC & 7 & 4 & 1 & 0 & 12 & 9 & 21 \\
\hline NEC without surgical procedure & 23 & 12 & 6 & 4 & 45 & 31 & 76 \\
\hline NEC without surgical procedure thereof deceased & 7 & 1 & 1 & 0 & 9 & 1 & 10 \\
\hline
\end{tabular}

ICD-10-GM, International classification of diseases-10, German modified. 
higher in the smallest infants $(\mathrm{BW}<750 \mathrm{~g}$ : $7.87 \%$ ) compared to those with a BW between 1250 and $1499 \mathrm{~g}(0.72 \%)$. In infants with a BW between 1000 and $1249 \mathrm{~g}$, the frequency of NEC (2.29\%) was more than three times higher and the frequency of FIP $(0.80 \%)$ more than two times higher than in those with a BW between 1250 and $1499 \mathrm{~g}$.

In Figure 2 the frequencies of acquired intestinal diseases in VLBW infants with a BW $<1250$ $\mathrm{g}$ are shown for 37 hospitals which had submitted at least one relevant dataset regarding FIP and/or NEC to $\mathrm{GeQiK}^{\circledR}$ during the years 2010, 2011 , or 2012. Hospital volume, i.e., the total number of infants with a $\mathrm{BW}<1250 \mathrm{~g}$ treated in that hospital is depicted on the $\mathrm{X}$-axis. Disease frequency normalized by its respective regional average per 100 infants with a $\mathrm{BW}<1250 \mathrm{~g}$ is plotted on the $\mathrm{Y}$-axis. Figure 2A shows the variations in frequencies of FIP between hospitals. Absolute FIP frequencies varied from 0 to 6.5\%, the empirical coefficient of variation was 1.3315. The highest frequency amounted to 2.9 times the average regional FIP rate of $2.3 \%$ (55 cases in 2439 infants). Normalized FIP frequencies did not significantly correlate with hospital volume.

Figure 2B shows the variations in frequencies of NEC between hospitals. Absolute NEC frequencies varied from 0 to $12.1 \%$, the empirical coefficient of variation was 1.1218. The highest frequency amounted to 2.5 times the average regional NEC rate of $4.9 \%$ (120 cases in 2439 infants). Normalized NEC frequencies also did not significantly correlate with hospital volume.

\section{Discussion and Conclusions}

This is the first population-based analysis of the epidemiology of acquired intestinal disease of preterm infants in hospitals in BadenWürttemberg. Our data show that - during the years 2010 to 2012 - the most frequent surgical emergencies in VLBW infants, NEK and FIP were diagnosed more often in infants with a $\mathrm{BW}<1250 \mathrm{~g}$ compared to those with a higher BW. The rule imposed by the G-BA, that PNC level 1 have to guarantee appropriate structures for immediate surgical treatment including the availability of qualified surgeons for these patients, can thus be based on external evidence: the BW limit of $1250 \mathrm{~g}$, which distinguishes PNC 1 and PNC 2 (Supplementary Table 1), ${ }^{1}$ also differentiates groups of patients with clearly distinguished risks for NEC and FIP and different requirements for surgical interventions.

NEC is thought to represent the most frequent emergency in neonatology caused by intestinal disease and it is commonly assumed that emergencies such as intestinal perforation due to FIP and NEC need immediate inter- vention by a qualified surgeon. ${ }^{7}$ Shorter intervals between the first symptoms, diagnosis, and surgical repair may improve survival, may reduce the need for complex surgical interventions, and may lead to less long-term morbidity, e.g., short bowel syndrome. Early consultation of the neonatologist and the pediatric surgeon may not necessarily result in more surgery; rather, it may result in prolongation of conservative treatment and watchful waiting without missing the appropriate time for surgery. $4,7,11$ Recently, Linge et al. ${ }^{13}$ have shown that not every preterm infant with gastrointestinal symptoms has FIP or NEC or requires surgery. In 7.9 to $10.8 \%$ VLBW infants with $\mathrm{BW}<1000 \mathrm{~g}$ FIP or NEC were diagnosed, but approximately twice that number had shown symptoms which were indicative of these diseases. Thus, 1 in 5 preterm infants with $\mathrm{BW}<1000 \mathrm{~g}$ may need consultation with pediatric surgeons during early stages of acquired gastrointestinal disease. Appropriate structures needed to effectively treat these patients on-site may comprise an operation

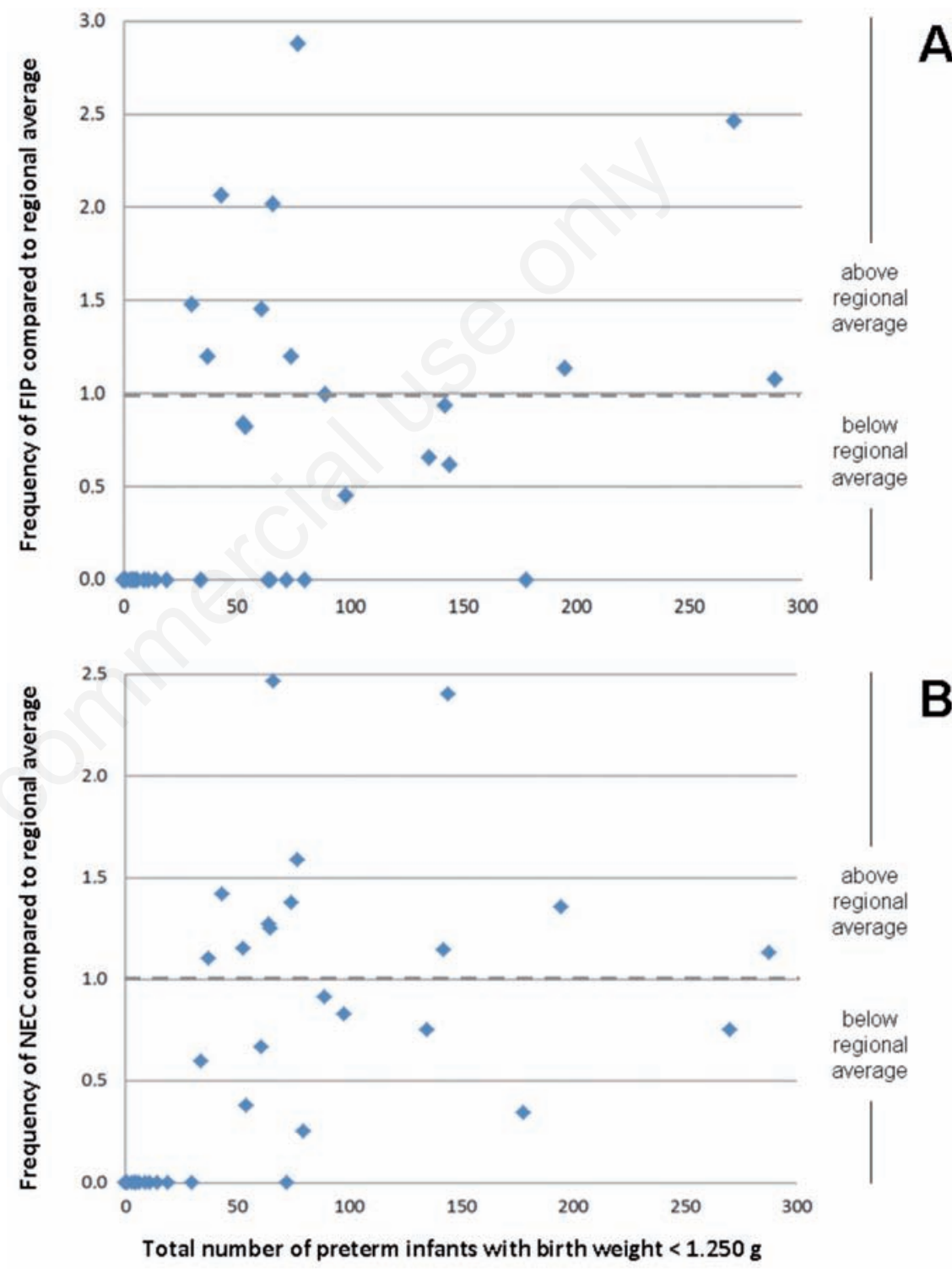

Figure 2. Diagnosis of acquired intestinal diseases in VLBW infants with a $B W<1250 \mathrm{~g}$ in 37 hospitals in Baden-Württemberg during the years 2010 to 2012. Each diamond represents disease frequency in a single hospital, normalized by the cumulative regional frequency per 100 infants with $\mathrm{BW}<1250 \mathrm{~g}$ (regional average) and depicted as a function of the total number of infants documented in the respective data sets. A) Hospital-specific rates of focal intestinal perforation (FIP), divided by the average regional FIP frequency $(2.18 \%)$, which is indicated by the broken horizontal line (1.0 value on the Y-axis). B) Hospital-specific rates of necrotizing enterocolitis (NEC), divided by the regional NEC frequency $(4.9 \%)$, which is indicated by the broken horizontal line (1.0 value on the Y-axis). 
theatre whose room temperature can be raised to $28^{\circ} \mathrm{C}$, ${ }^{1}$ warming mattress and overhead heat radiator suitable for VLBW, special equipment for anesthesiologists and special surgical instruments, as well as the availability of anesthesiologists experienced in peri- and intraoperative handling of VLBW. ${ }^{4}$

Our data are in accordance with reports in the literature. Sankaran et al. ${ }^{8}$ found that NEC incidence in Canada decreased with increasing BW: among infants with a BW between 501 and $1000 \mathrm{~g}$ the incidence was $11.2 \%$, compared to $4.3 \%$ in infants with a BW between 1001 and $1500 \mathrm{~g}$, and below $2 \%$ in infants with a BW above $1500 \mathrm{~g}$. The risk to acquire NEC was nearly doubled in infants with a gestational age $<28$ weeks compared to those aged 28 weeks and above (odds ratio 1.9; $95 \%$ confidence interval 1.4 to 2.7). The data set of the national German reference center for surveillance of nosocomial infection in the years 2008 to 2012 yields a cumulative 5 -year NEC incidence of $6 \%$ in infants with a $\mathrm{BW}<500 \mathrm{~g}$ $(83 / 1313)$, of $4.8 \%$ in infants with a BW from 500 to $999 \mathrm{~g}(640 / 13,220)$, and of $1.3 \%$ in infants with a BW from 1000 to $1499 \mathrm{~g}$ $(259 / 30,716) .15$ Thus, both nationally and internationally, published NEC rates are comparable to our data.

To our knowledge, no population-based studies of the epidemiology of FIP in preterm infants have been performed in Germany. Eicher et al. ${ }^{16}$ reported in a single center study on 28 out of 280 preterm infants with a $\mathrm{BW}<1000 \mathrm{~g}$ who underwent surgery for acquired intestinal disease between 2002 and 2007 (19 with FIP, 9 with NEC). In an observational study from Japan, Okuyama et al. ${ }^{5}$ reported on 39 VLBW infants who underwent laparotomy during previous 20 years; 19 of them had NEC, and 8 had FIP. Eicher et al. 16 comment on their FIP rate $(6.6 \%$ in inborn preterm infants $<1000 \mathrm{~g} \mathrm{BW}$ ), which is increased compared to international data, that there may be more awareness regarding the distinction of NEC and FIP, leading to a perceived increase in FIP frequency in more recent studies.

Frequencies of FIP and NEC differ between the NICUs in Baden-Württemberg and range from no cases at all to 2.5 times the regional mean for NEC and 2.9 times the regional mean for FIP. The coefficients of variation of the frequencies of these diagnoses between the hospitals are rather low. 17 Variability may be explained by i) difficulties in clinical differential diagnosis without surgical intervention, 13 ii) differences in preventive strategies such as infant feeding regimes, ${ }^{18}$ or the use of probiotics. ${ }^{19}$ However, our study is limited by general data quality of the neonatal dataset including the problem of small numbers. ${ }^{20}$ In addition, a NICU without on-site availability of pediatric surgeons may transfer infants to PNC with such a service before a definitive diagno- sis is made. Thus, diagnoses may be missed after transfer of a patient to another hospital (underreporting) and in units with low patient volume the frequency of FIP and NEC may be underestimated, or a patient may be included in 2 data sets (overreporting).

Hunter et al. ${ }^{7}$ noticed that, during the past 20 years, there was no significant improvement in mortality and morbidity of VLBW infants related to acquired gastrointestinal disease despite the general progress in neonatal intensive care. Overall improvements in treatment outcome of VLBW infants may require a better understanding of pathogenesis, prevention, and treatment of these diseases. At the moment, possible next steps in quality assurance in neonatal wards in BadenWürttemberg may therefore consist in a structured dialogue with the contributing hospitals about differences in the strategies they adopt to prevent NEC and FIP based on an epidemiologic analysis over a period of 5 years.

\section{References}

1. Gemeinsamer Bundesausschuss. Beschluss über eine Änderung der Vereinbarung über Maßnahmen zur Qualitätssicherung der Versorgung von Früh- und Neugeborenen vom 20. Juni 2013.

2. Gordon PV, Swanson JR, Attridge JT, Clark R. Emerging trends in acquired neonatal intestinal disease: is it time to abandon Bell's criteria? J Perinatol 2007;27:661-71.

3. Nowicki PT. Ischemia and necrotizing enterocolitis: where, when, and how. Semin Pediatr Surg 2005;14:152-8

4. Pumberger W, Mayr M, Kohlhauser C, Weninger M. Spontaneous localized intestinal perforation in very-low-birth-weight infants: a distinct clinical entity different from necrotizing enterocolitis. J Am Coll Surg 2002;195:796-803.

5. Okuyama H, Kubota A, Oue T, et al. A comparison of the clinical presentation and outcome of focal intestinal perforation and necrotizing enterocolitis in very-low-birthweight neonates. Pediatr Surg Int 2002;18:704-6.

6. Sharma R, Hudak ML, Tepas JJ 3rd, et al. Prenatal or postnatal indomethacin exposure and neonatal gut injury associated with isolated intestinal perforation and necrotizing enterocolitis. J Perinatol 2010;30:786-93.

7. Hunter CJ, Chokshi N, Ford HR. Evidence vs experience in the surgical management of necrotizing enterocolitis and focal intestinal perforation. J Perinatol 2008;28 Suppl 1:S14-7

8. Sankaran K, Puckett B, Lee DSC, et al. Variations in incidence of necrotizing enterocolitis in Canadian neonatal intensive care units. J Pediatr Gastroenterol Nutr 2004;39:366-72.

9. Gemeinsamer Bundesausschuss. Richtlinie gemäß § 137 Abs. 1 SGB V i.V.m. § 135a SGB V über Maßnahmen der Qualitätssicherung für nach $\S 108$ SGB V zugelassene Krankenhäuser (Richtlinie über Maßnahmen der Qualitätssicherung in Krankenhäusern - QSKH-RL) in der Fassung vom 15. August 2006 veröffentlicht im Bundesanzeiger Nr. 178 (S. 6 361) vom 20. September 2006, in Kraft getreten am 1. Januar 2007, zuletzt geändert am 16. August 2012 veröffentlicht im Bundesanzeiger (BAnz AT 20.11.2012 B4), tritt in Kraft am 1. Januar 2013.

10. Clemens T. Grundlegende Fragen des Schiedsverfahrens nach dem KHG. MedR 2012;30:769-77.

11. Gesellschaft für Neonatologie und Pädiatrische Intensivmedizin (GNPI). Nekrotisierende Enterokolitis (NEK). AWMF-Leitlinien-Register Nr. 024/009.

12. Deutsche Krankenhausgesellschaft. Vereinbarung gemäß § 301 Abs. 3 SGB V über das Verfahren zur Abrechnung und Übermittlung der Daten nach $\S 301$ Abs. 1 SGB V (Datenübermittlungsvereinbarung $\S 301$ ).

13. Linge M, Mayatepek E, Höhn T. Fokal intestinale Perforation vs. nekrotisierende Enterokolitis bei Frühgeborenen mit einem Geburtsgewicht <1500 g: zwei Entitäten oder unterschiedliche Ausprägungen eines Krankheitsbildes? Monatsschr Kinderheilkd 2013;161 Suppl 1:76.

14. Frei FJ, Erb T, Jonmarker C, et al. Kinderanästhesie. 3. Aufl., Heidelberg: Springer; 2004.

15. Nationales Referenzzentrum für Surveillance von nosokomialen Infektionen. Krankenhaus-Infektions-Surveillance-System (KISS) Modul NEO KISS Referenzdaten Januar 2008 bis Dezember 2012.

16. Eicher C, Seitz G, Bevot A, et al. Surgical management of extremely low birth weight infants with neonatal bowel perforation: a single-center experience and a review of the literature. Neonatology 2012;101:285-92.

17. Wennberg JE. Tracking medicine: a researcher's quest to understand health care. Oxford: Oxford University Press; 2004.

18. Morgan J, Young L, McGuire W. Slow advancement of enteral feed volumes to prevent necrotising enterocolitis in very low birth weight infants. Cochrane Database Syst Rev 2013;3:CD001241.

19. Alfaleh K, Bassler D. Probiotics for prevention of necrotizing enterocolitis in preterm infants. Cochrane Database Syst Rev 2008:CD005496.

20. Dimick JB, Welch HG, Birkmeyer JD. Surgical mortality as an indicator of hospital quality: the problem with small sample size. JAMA 2004;292:847-51. 